\title{
Thermal Shock Behavior Analysis of Tungsten-Armored Plasma-Facing Components for Future Fusion Reactor
}

\author{
Shu-Ming Wang ${ }^{1} \cdot$ Jiang-Shan $\mathrm{Li}^{1} \cdot$ Yan-Xin Wang ${ }^{1} \cdot$ Xiao-Fang Zhang $^{1} \cdot \mathrm{Qing}^{\mathrm{Y}}{ }^{1}$ \\ Received: 7 February 2018/Revised: 8 March 2018/Published online: 28 March 2018 \\ (C) The Chinese Society for Metals and Springer-Verlag GmbH Germany, part of Springer Nature 2018
}

\begin{abstract}
In a fusion reactor, plasma-facing components (PFCs) will suffer severe thermal shock; behavior and performance of PFCs under high heat flux (HHF) loads are of major importance for the long-term stable operation of the reactor. This work investigates the thermo-mechanical behaviors of tungsten armor under high heat loads by the method of finite element modeling and simulating. The temperature distribution and corresponding thermal stress changing rule under different HHF are analyzed and deduced. The Manson-Coffin equation is employed to evaluate the fatigue lifetime (cyclic times of HHF loading) of $\mathrm{W}$-armored first wall under cyclic HHF load. The results are useful for the formulation design and structural optimization of tungsten-armored PFCs for the future demonstration fusion reactor and China fusion experimental thermal reactor.
\end{abstract}

Keywords Plasma-facing components · Thermo-mechanical behavior · High heat flux · Tungsten armor · Fatigue lifetime $\cdot$ Finite element method

\section{Introduction}

Fusion energy produced by the interaction of high-temperature plasmas is a promising way to solve the human energy crisis. In the thermonuclear fusion reactor, the plasma-facing components (PFCs) are the first barrier to protect the vacuum chamber wall and various internal components from direct high-temperature plasma irradiation $[1,2]$. The plasma-facing materials (PFMs) will suffer the irradiation of high heat flux from the plasma up to $5-20 \mathrm{MW} / \mathrm{m}^{2}$. In addition, the high-energy ions and neutral atoms escaping from the plasma can lead to severe ablation of the heated PFMs, which will result in the failure of plasma-facing materials and cause plasma contamination $[3,4]$. Therefore, the structural integrity of PFMs can affect the service life of PFCs, the stability of the plasma and even the security of the entire fusion reactor. The PFCs are generally composed of PFMs, interlayer and heat sink

Available online at http://link.springer.com/journal/40195.

Shu-Ming Wang

wangshuming@ustb.edu.cn

1 Department of Materials Science and Engineering, University of Science and Technology Beijing, Beijing 100083, China materials. Reasonable selection of PFMs and design of PFCs are critical to the realization of controlled thermonuclear fusion power. During the last decades, the most fusion devices with moderate magnetic field and plasma densities have selected low-Z beryllium or carbon-based materials as PFM [5]. However, the main limitations of low-Z PFMs are their heavy erosion under high heat flux (HHF). Therefore, with the further development of fusion reactor, especially the large-scale devices [6], the high- $\mathrm{Z}$ materials are selected as alternative candidates, among which tungsten (W) is the most promising one because of its many unique advantages such as high melting point $\left(3420^{\circ} \mathrm{C}\right)$, low sputtering erosion and negligibly small tritium retention, comparatively high thermal conductivity and moderate thermal expansion [7]. Tungsten has been chosen as the main divertor PFMs in international thermal experimental reactor (ITER) and has been foreseen as the most suitable candidate for the first wall in demonstration fusion reactor (DEMO) or future fusion reactors [5, 8]. The $\mathrm{CuCrZr}$ alloy with high thermal conductivity and good irradiation resistance has been recommended as the heat sink materials and the oxygen-free high-conductivity copper (OFHC-Cu) is selected as an interlayer material to join the PFMs and $\mathrm{CuCrZr}$ heat sink materials for reducing the 
thermal stress caused by large differences of thermalphysical properties of the PFMs and $\mathrm{CuCrZr}$ [9-12].

Many numerical simulations or experimental researches on different plasma-facing materials under ITER-relevant high heat flux or other various heat loads have been carried out. Dell'Orco et al. [13] researched the thermal-mechanical calculations for Beryllium first wall (FW) mock-ups under a heat flux of $0.8 \mathrm{MW} / \mathrm{m}^{2}$. Hirai et al. [14] calculated the temperature distribution of a tungsten-based PFM under HHF. It demonstrated that in the case of 10-mm-thick W armor, the surface temperature of PFCs reaches about $2500{ }^{\circ} \mathrm{C}$ at the steady-state heat flux of $20 \mathrm{MW} / \mathrm{m}^{2}$. Roeding et al. [15] performed the thermal fatigue experiments on four different tungsten mock-ups for ITER divertor by means of the e-beam facility JUDITH. Different designs of monoblock mock-ups performed as well as a W macrobrush mock-up at power densities at 14-20 MW/ $\mathrm{m}^{2}$ (absorbed). For two W plasma-sprayed mock-ups, failure will occur when the heat flux barely reached up to 6.5 MW/ $\mathrm{m}^{2}$. Huang et al. [16] studied the coupled thermal/ mechanical calculations for two ITER-like PFMs of Be and functionally graded $\mathrm{W}-\mathrm{Cu}$, respectively, under the high heat flux of $1-2 \mathrm{GW} / \mathrm{m}^{2}$ for $10 \mathrm{~ms}$ and found that heat is mainly deposited on the PFM layer in the thermal shock pulse, causing the complex thermal stress changes and irreversible mechanical damages. Gavila et al. [17] evaluated the performance of $\mathrm{W}$ mock-ups and medium-scale prototypes of divertor under HHF using an electron beam test facility.

This work aims to systematically investigate the changing rule and tending of temperature/stress of tungsten-armored FW under different HHF, and to analyze the thermal shock resistance performance of tungsten-armored FW under HHF. Besides, the numerical simulations of thermal fatigue life for tungsten-armored FW are also evaluated. Researches are of great significance for the structural design of PFCs and the formulation of work system of DEMO, China fusion experimental thermal reactor (CFETR) or other future fusion reactor.

\section{FE Model}

\subsection{Geometry, FE Mesh and Materials}

The typical ITER-like FW mock-up is shown in Fig. 1 [18]. In this work, the beryllium (Be) armor is replaced by tungsten, and we selected a feature unit from the central area of FW mock-up as the PFC model for simplifying the $\mathrm{FE}$ analysis. The 3-D geometric structure, dimensions and constituted materials of the considered PFC model are shown in Fig. 2, and Fig. 3 is the corresponding finite element mesh. The dimension of tungsten armor is

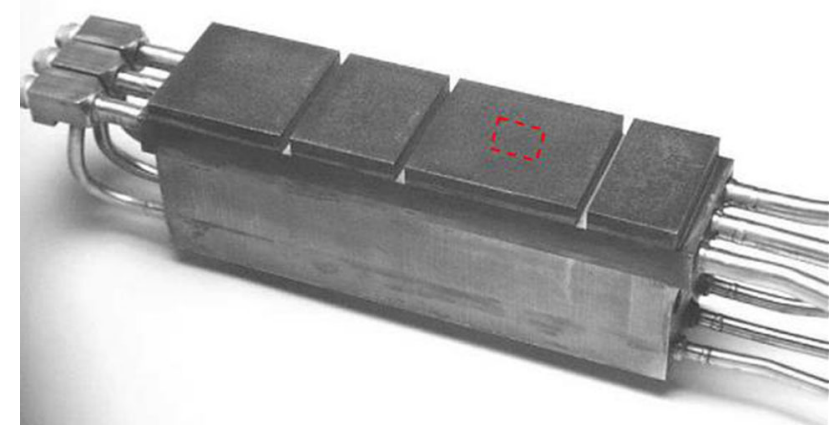

Fig. 1 FW mock-up with hot-isostatic-pressed Be tiles

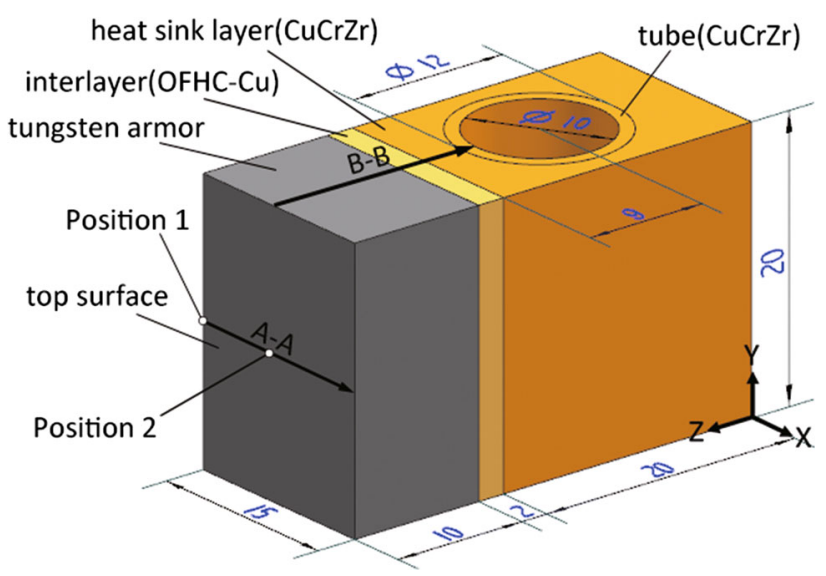

Fig. 2 Sketch map of the PFC model size and two paths

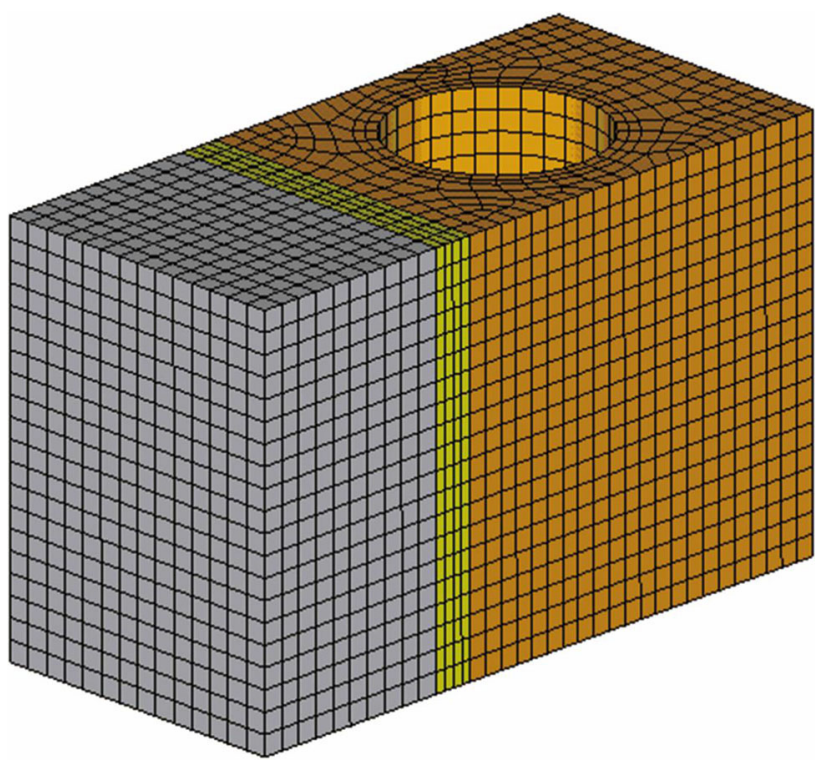

Fig. 3 Corresponding FE mesh of the mock-up

$15 \mathrm{~mm} \times 20 \mathrm{~mm} \times 10 \mathrm{~mm}$, the thickness of $\mathrm{CuCrZr}$ cooling tube is $1 \mathrm{~mm}$, and the inner diameter is $10 \mathrm{~mm}$. There is an OFHC-Cu interlayer between the tungsten 
armor and the $\mathrm{CuCrZr}$ heat sink layer, which is used to reduce the jointing stress $[14,19]$.

Thermo-mechanical behaviors of tungsten-armored PFCs under different HHF were analyzed by FE package ANSYS [20-23]. The thermal-physical properties of selected materials in the model are listed in Table 1, and the parameters were referred from ITER material properties handbook [24] and related documents [25-28]. Besides, perfect thermal contacts at the interfaces were assumed.

\subsection{Loads and Boundary Conditions}

The ITER-relevant cooling condition was selected: $\sim 10$ $\mathrm{m} / \mathrm{s}, 4.2 \mathrm{MPa}$ and $120{ }^{\circ} \mathrm{C}[14,29]$. In the analysis of $\mathrm{FE}$, stress and strain distributions of the PFC model were obtained by indirect coupling method, the heat fluxes were uniformly applied to the top surface of the model, and initial temperature of the model is set as $20^{\circ} \mathrm{C}$. In addition, the coefficient of convection heat transfer (CCHF) of the inner wall of the cooling tube and the coolant water is $55,000 \mathrm{~W} /\left(\mathrm{m}^{2} \mathrm{~K}\right)$, which is derived from the well-known Dittus-Boelter formula [30]. Finally, symmetric boundary conditions (i.e., heat exchange is the state of equilibrium) were applied to other surfaces, and a pressure of $4.2 \mathrm{MPa}$ of the inner surface of cooling tube was applied to simulate the pressure caused by cooling water [31].

\section{Steady-State Heat Flux Simulation}

\subsection{Temperature Fields}

The temperature distribution of designed PFC model under different heat fluxes $\left(2-25 \mathrm{MW} / \mathrm{m}^{2}\right)$ was calculated and shown in Fig. 4. It can be found that the temperature field of the model is symmetric to the $Y-Z$ plane which coincides with the axis of cooling tube. Additionally, the temperature gradient of tungsten armor increased gradually as the increase in heat flux. What caused such phenomenon is that the heat of tungsten surface cannot be transferred in time due to the relatively low conductivity of tungsten. Therefore, a large amount of heat will be accumulated at the $\mathrm{W}$-armored layer. Moreover, the decrease in thermal conductivity resulted from the increase in temperature will accelerate the increase in the temperature of $\mathrm{W}$ armor. The temperature of $\mathrm{W}$ armor will increase to about $3150{ }^{\circ} \mathrm{C}$ when the steady-state heat flux goes up to $25 \mathrm{MW} / \mathrm{m}^{2}$. To prevent $\mathrm{W}$ from melting (the melting point of $\mathrm{W}$ is $3420{ }^{\circ} \mathrm{C}$ ), the maximum heat flux should not exceed about $27 \mathrm{MW} / \mathrm{m}^{2}$, which is estimated according to the relationship between the heat flux and surface temperature of $\mathrm{W}$ armor.

Path A-A is a hypothetical horizontal path passing through the center point of top surface (Fig. 2). Figure 5 presents the distribution of the temperature along the path $\mathrm{A}-\mathrm{A}$ at 5 and $25 \mathrm{MW} / \mathrm{m}^{2}$. The results indicate that, in the direction of cooling tube axis, the temperature at both sides of tungsten armor is always higher than center area. Therefore, at the edges of tungsten armor, the phenomenon

Table 1 Thermal-physical properties of the considered materials at selected temperatures

\begin{tabular}{|c|c|c|c|c|c|c|c|}
\hline Material & $\begin{array}{l}\text { Temperature } \\
\left({ }^{\circ} \mathrm{C}\right)\end{array}$ & $\begin{array}{l}\text { Thermal conductivity } \\
\left(\mathrm{W} \mathrm{m}{ }^{-1} \mathrm{~K}^{-1} \text { ) }\right.\end{array}$ & $\begin{array}{l}\text { Coefficient of thermal } \\
\text { expansion }\left(10^{-6} \mathrm{~K}^{-1}\right)\end{array}$ & $\begin{array}{l}\text { Young's } \\
\text { modulus (GPa) }\end{array}$ & $\begin{array}{l}\text { Poisson's } \\
\text { ratio }\end{array}$ & $\begin{array}{l}\text { Yield } \\
\text { strength } \\
(\mathrm{MPa})\end{array}$ & $\begin{array}{l}\text { Tangent } \\
\text { modulus (GPa) }\end{array}$ \\
\hline \multirow[t]{7}{*}{ W } & 20 & 173 & 4.5 & 398 & 0.28 & 1360 & 1.3 \\
\hline & 200 & 156 & - & 396 & - & 1154 & - \\
\hline & 500 & 133 & 4.7 & 390 & - & 854 & 1 \\
\hline & 800 & 118 & - & 379 & 0.29 & 604 & - \\
\hline & 1000 & 111 & 5.1 & 368 & - & 465 & 0.8 \\
\hline & 1500 & 101 & 5.6 & 333 & 0.30 & 204 & - \\
\hline & 1800 & 99 & 5.8 & 306 & - & 103 & - \\
\hline \multirow[t]{4}{*}{ OFHC } & 20 & 403 & 16.7 & 125 & 0.34 & 69 & 1.5 \\
\hline & 200 & 392 & 17.2 & 115 & & 60 & 1.3 \\
\hline & 400 & 379 & 17.8 & 100 & & 48 & 0.9 \\
\hline & 700 & 360 & 18.9 & 70 & & 30 & 0.6 \\
\hline \multirow[t]{3}{*}{$\mathrm{CuCrZr}$} & 20 & 326 & 16.7 & 128 & 0.32 & 293 & 0.9 \\
\hline & 250 & 343 & 17.2 & 118 & 0.42 & 257 & 0.7 \\
\hline & 500 & 348 & 18.2 & 103 & 0.52 & 195 & 0.6 \\
\hline
\end{tabular}



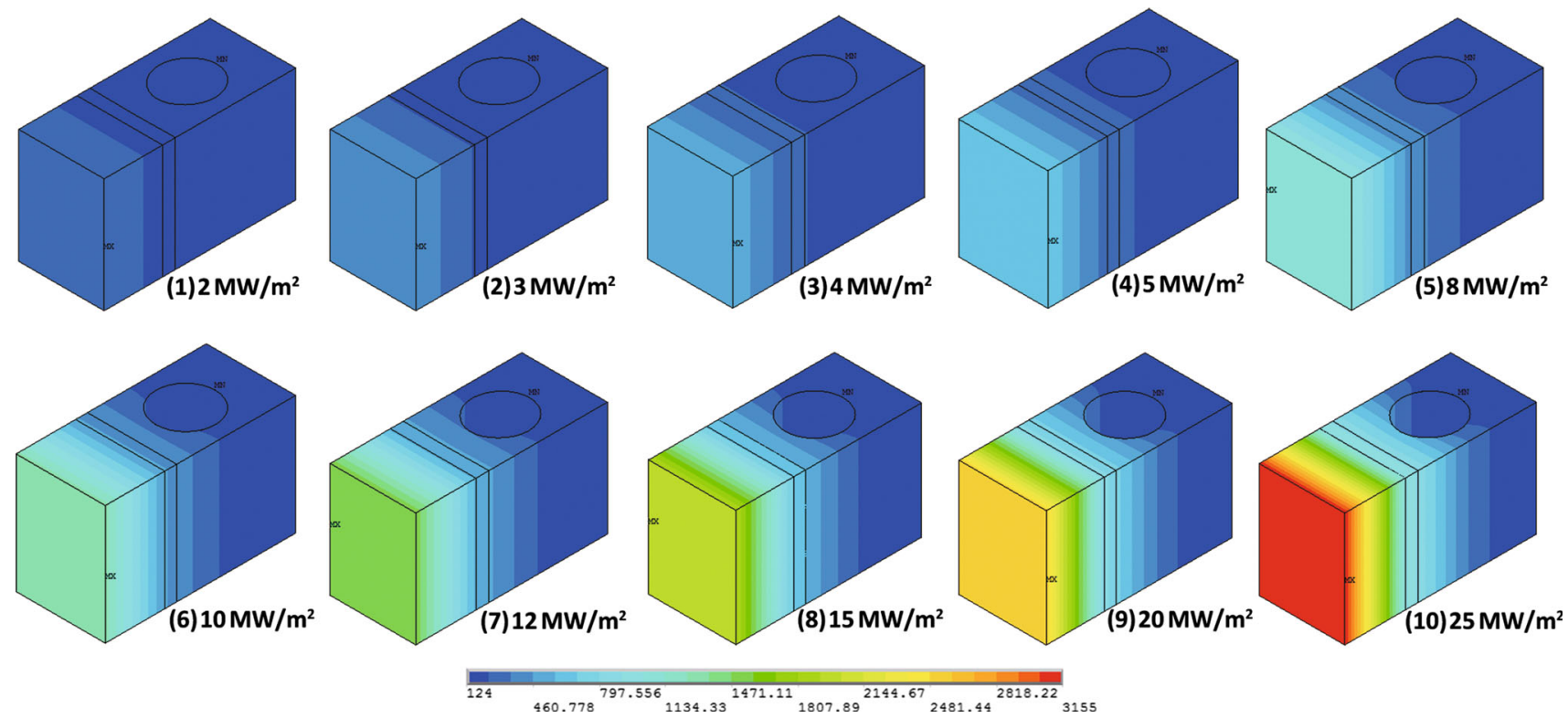

Fig. 4 Temperature contour plots under different heat fluxes
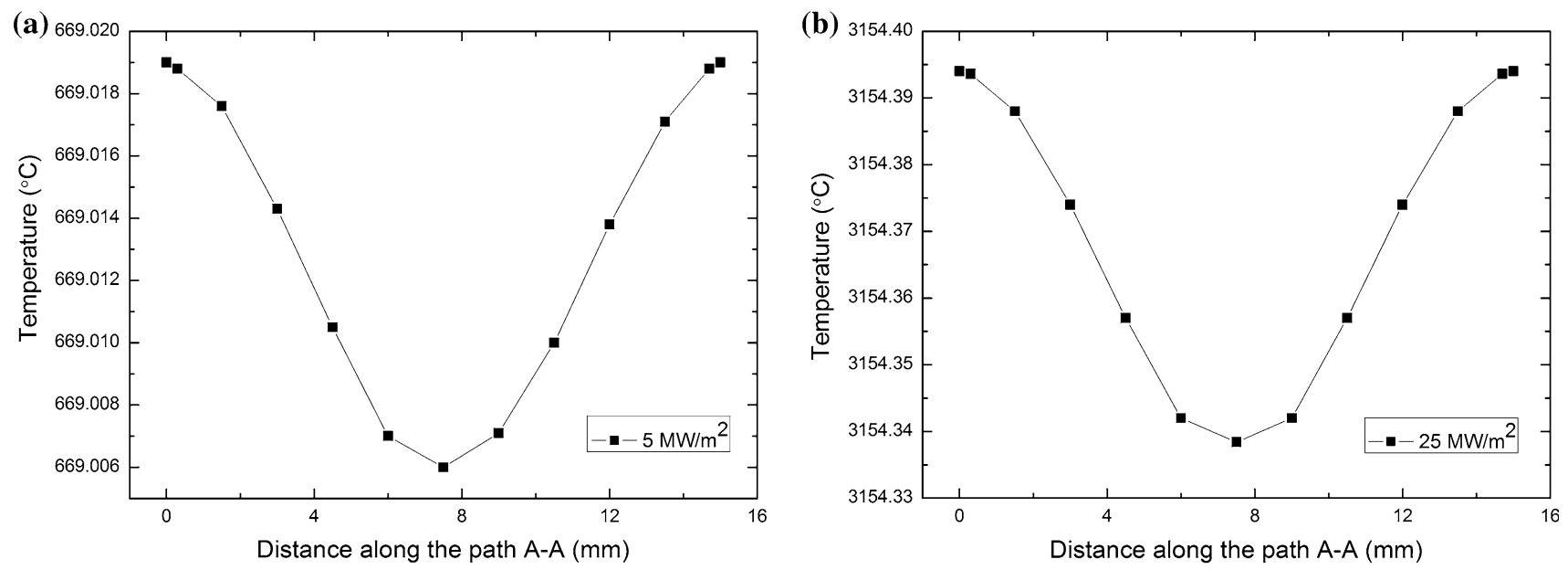

Fig. 5 Distribution of temperature along the path A-A at different heat flux values: (a) $5 \mathrm{MW} / \mathrm{m}^{2}$, (b) $25 \mathrm{MW} / \mathrm{m}^{2}$

of surface roughening or melting induced by the temperature and plastic deformation is much more significant. The simulation results agree with the high heat flux test results at electron beam test facilities conducted by Gavila et al. [17].

\subsection{Stress Fields}

Figure 6 displays von Mises equivalent stress contour plots under different HHFs. It can be seen that the stress concentration zone (SCZ) formed on the top surface of the $\mathrm{W}$ armor, and gradually moved toward OFHC-Cu interlayer with increasing heat flux. Eventually, the SCZ stabilizes at the junction of $\mathrm{W}$-armor layer and $\mathrm{OFHC}-\mathrm{Cu}$ interlayer, and then the stress value decreased gradually. The reason is that the Young's modulus of tungsten is very high at relative low temperatures, and the increase in compression stress induced by thermal expansion of this material is larger than the decrease in strength induced by the temperature increase result in the von Mises equivalent stress increase. On the contrary, the Young's modulus significantly decrease as the temperature increases highly, the von Mises equivalent stress will decrease when the increase in the compression stress induced by thermal expansion cannot offset the decrease in material strength. Furthermore, it can be found that the von Mises equivalent stress at the whole tungsten armor layer was almost evenly distributed, when the heat flux is up to $25 \mathrm{MW} / \mathrm{m}^{2}$. This phenomenon suggests that the tungsten armor has taken on yield behavior, while the Young's modulus of tungsten has 

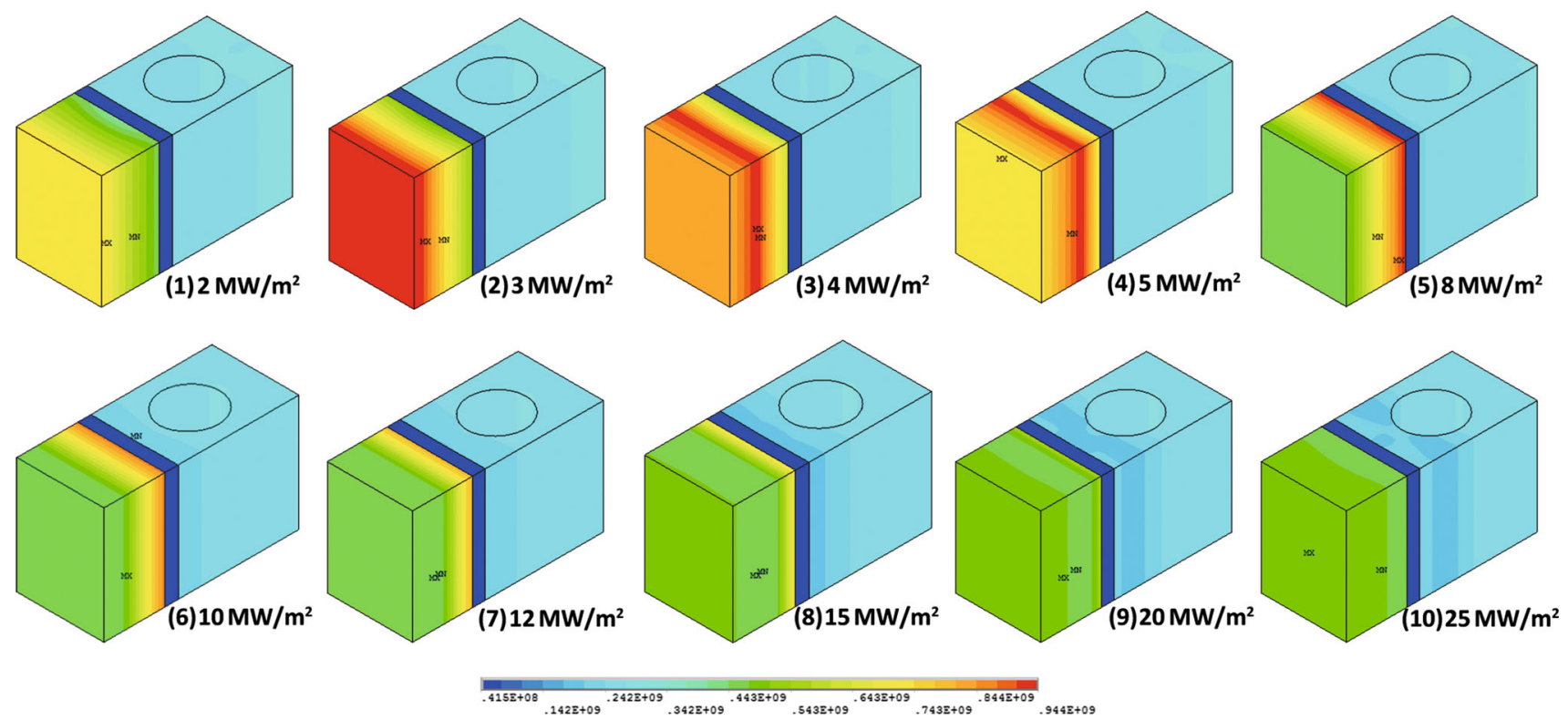

Fig. 6 Von Mises equivalent stress contour plots under different high heat fluxes

hardly changed with the rise of the temperature. In general, the phenomenon of stress variation is the result of the combination of the Young's modulus change and the yield of tungsten armor.

Path B-B is another horizontal path which passes through the center point of cooling tube. Figure 7a shows the distribution of von Mises equivalent stress along the path $\mathrm{B}-\mathrm{B}$ at $2-10 \mathrm{MW} / \mathrm{m}^{2}$, and Fig. $7 \mathrm{~b}$ shows the corresponding temperature distribution. The maximum stress value is always on the top surface when the heat flux is less than $3 \mathrm{MW} / \mathrm{m}^{2}$ (the temperature on the top surface is about $420{ }^{\circ} \mathrm{C}$ ), and the Mises equivalent stress is in proportion to the temperature. When the heat flux is larger than $3 \mathrm{MW} /$ $\mathrm{m}^{2}$, the SCZ will gradually move toward OFHC-Cu interlayer with increasing heat flux. Moreover, it should be noted that the temperature corresponding to the moving SCZ is about $420{ }^{\circ} \mathrm{C}$. Therefore, we can deduce that the $\mathrm{SCZ}$ reached to the junction of $\mathrm{W}$-armor layer and OFHC$\mathrm{Cu}$ interlayer when the heat flux is up to $9 \mathrm{MW} / \mathrm{m}^{2}$. In other words, the largest stress difference between the armor layer and interlayer occurred when the heat flux is about $9 \mathrm{MW} / \mathrm{m}^{2}$.

Similarly, Fig. 8a shows the distribution of von Mises equivalent stress along the path B-B at $8-25 \mathrm{MW} / \mathrm{m}^{2}$, and Fig. $8 \mathrm{~b}$ shows the corresponding distribution of temperature. It can be found that the top surface of the designed PFC begun to yield at $8 \mathrm{MW} / \mathrm{m}^{2}$ (the temperature and stress of top surface is about $1050{ }^{\circ} \mathrm{C}$ and $470 \mathrm{MPa}$ ), and the thickness of yield layer increased gradually with increasing heat flux. Eventually, the whole tungsten armor layer yielded when the heat flux is up to $25 \mathrm{MW} / \mathrm{m}^{2}$. It
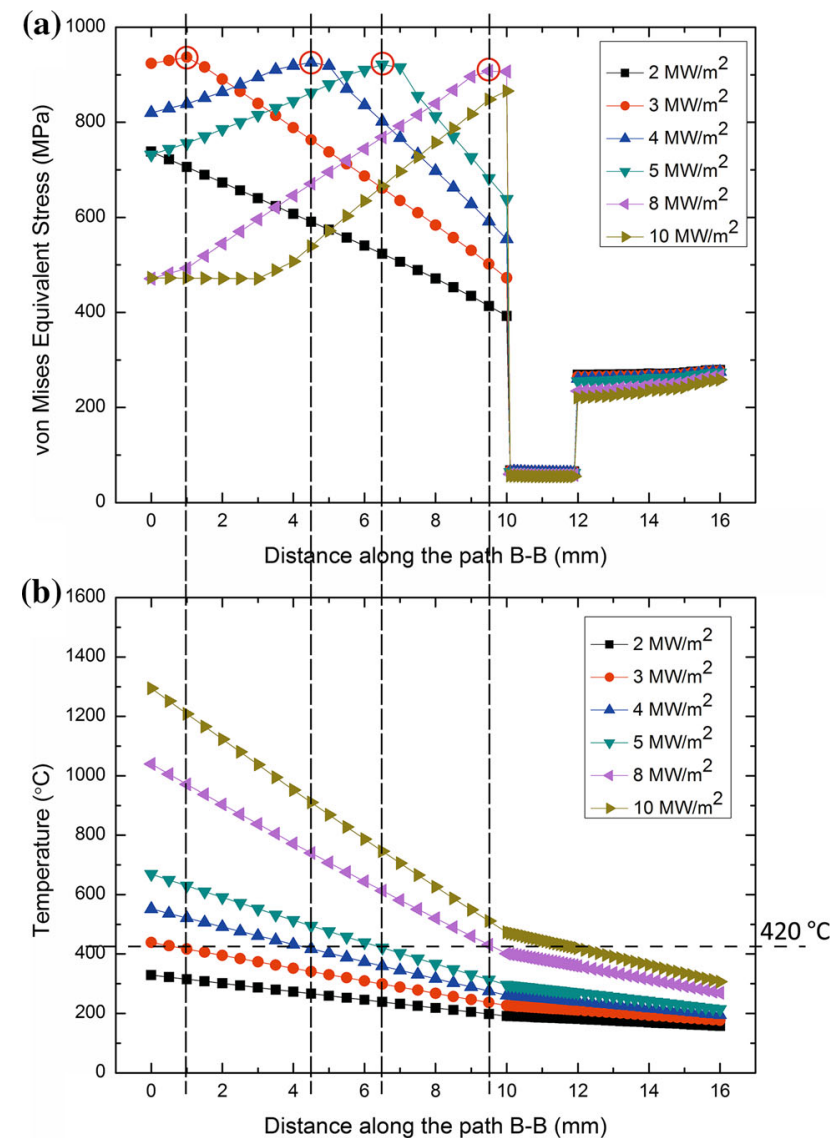

Fig. 7 Distribution of von Mises equivalent stress (a), temperature (b) along the path $\mathrm{B}-\mathrm{B}$ at $2-10 \mathrm{MW} / \mathrm{m}^{2}$

should be noted that the temperatures corresponding to all the yield points all are about $1050{ }^{\circ} \mathrm{C}$. 


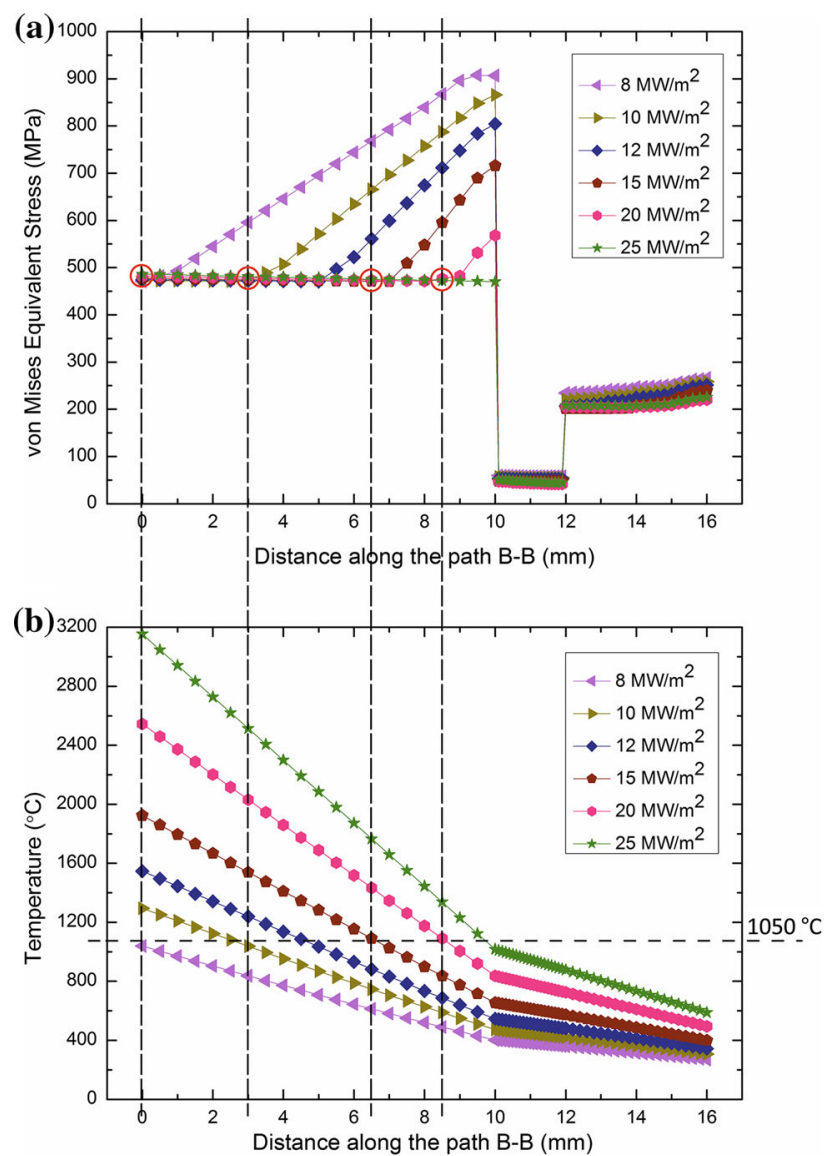

Fig. 8 Distribution of von Mises equivalent stress (a), temperature (b) along the path B-B at $8-25 \mathrm{MW} / \mathrm{m}^{2}$

\section{Fatigue Lifetime Analysis}

Thermal fatigue is also a key issue that should be concerned when the PFCs are in service. In this work, HHF load cycles are simulated and each cycle includes $30 \mathrm{~s}$ of HHF loading and $10 \mathrm{~s}$ of cooling. The initial temperature is $120{ }^{\circ} \mathrm{C}$ (cooling water temperature). The duration of the heating period depended on the time span when the heat equilibrium is established [3].

Figure 9 demonstrates the temperature changes at position 2 under different HHF loads (the temperature at position 1 is not showed here due to the similarity). Moreover, the variation of the temperature in each cycle is identical.

The thermal fatigue of tungsten armor is assumed to be a kind of low-cycle fatigue (LCF), and according to the theoretical research at high-temperature LCF [32], the Manson-Coffin equation is adopted to assess the LCF lifetime of tungsten armor. Equation (1) is the "strain-life" equation based on Manson-Coffin equations.

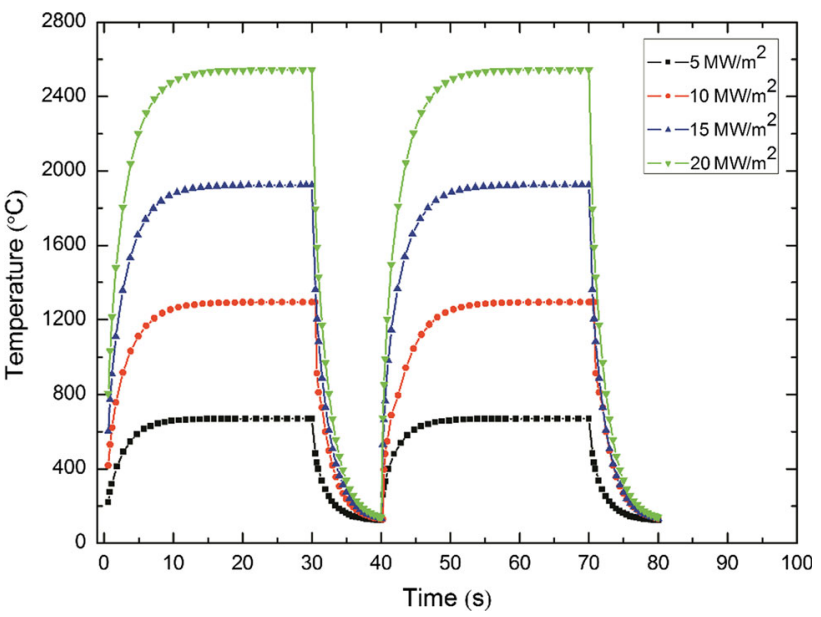

Fig. 9 Temperature variation at position 2 under different high heat fluxes

$\Delta \varepsilon_{\mathrm{t}}=\Delta \varepsilon_{\mathrm{e}}+\Delta \varepsilon_{\mathrm{p}}=3.5 \frac{\sigma_{b}}{E}\left(N_{\mathrm{f}}\right)^{b}+\varepsilon_{\mathrm{f}}^{0.6}\left(N_{\mathrm{f}}\right)^{c}$.

where $\Delta \varepsilon_{\mathrm{t}}$ is the total strain, $\Delta \varepsilon_{\mathrm{e}}$ is elastic strain, $\Delta \varepsilon_{\mathrm{p}}$ is plastic strain, $N_{\mathrm{f}}$ is the number of cycles to failure, $E$ is the modulus of elasticity, $\sigma_{b}$ is the fatigue strength, $b$ is the fatigue strength exponent, $c$ is the fatigue ductility exponent, and $\varepsilon_{\mathrm{f}}$ is the fatigue ductility coefficient. As for the LCF, the plastic contribution is dominant, only the plastic term of Eq. (1) was considered in the present analysis of $\mathrm{W}$-armor lifetime. Putting related parameters into Eq. (1) [33], the ultimate assessment equation of LCF lifetime is as follows: (2)

$\Delta \varepsilon_{\mathrm{p}}=0.5^{0.6}\left(N_{\mathrm{f}}\right)^{-0.6}$.

In addition, the position of maximum temperature and plastic strain for tungsten armor is located on the top surface of PFC, and fatigue cracks are very likely to initiate from the top surface. Therefore, two reference positions (position 1 and 2) are selected on the top surface to perform thermal fatigue analysis for tungsten armor (Fig. 2).

Table 2 lists the values of the equivalent plastic strain in an HHF load cycle and the calculated fatigue lifetime at position 1 and 2. There is no obvious difference in fatigue lifetime at two reference positions, for the relatively homogeneous temperature distribution on the top surface. In addition, the fatigue lifetime of $\mathrm{W}$ armor is exponential decreased with increasing heat flux, and the fatigue lifetime of $\mathrm{W}$ armor is about 330 when the heat flux is up to $20 \mathrm{MW} / \mathrm{m}^{2}$. However, it should be noted that the armor is very likely to generate cracks during cooling progress because of the high ductile to brittle transition temperature of tungsten [34]. So the actual fatigue lifetime is shorter than the predicted one. Besides, the fatigue lifetime at central area is slightly shorter than that of edges, and the cooling rate at the central area of tungsten surface is also 
Table 2 Equivalent plastic strain in an HHF load cycle and the predicted fatigue lifetime at positions 1 and 2

\begin{tabular}{llllr}
\hline Reference positions & \multicolumn{4}{l}{ High heat flux $\left(\mathrm{MW} / \mathrm{m}^{2}\right)$} \\
\cline { 2 - 5 } & 5 & 10 & 15 & \multicolumn{1}{l}{20} \\
\hline 1 & $0.2942 / 8285$ & $0.9429 / 1191$ & $1.4649 / 571$ & $2.0078 / 336$ \\
2 & $0.2944 / 8273$ & $0.9640 / 1158$ & $1.4991 / 548$ & $2.0055 / 325$
\end{tabular}

faster than that of edges. Therefore, the cracks are very likely to initiate in the central area of tungsten surface since the central area will reach to the ductile to brittle transition temperature firstly in the cooling progress. Furthermore, combining the temperature field of $\mathrm{W}$-armored PFC, we can infer that the growth direction of cracks is coincident with the direction of cooling tube axis.

\section{Conclusions}

1. The heat on the top surface of PFC could not be transferred in time because of relatively low thermal conductivity of tungsten. Therefore, more and more heat would be accumulated at the armor layer with increasing heat flux, and the temperature of tungsten surface is expected to reach the melting point $\left(3420{ }^{\circ} \mathrm{C}\right)$ when heat flux goes up to the $27 \mathrm{MW} / \mathrm{m}^{2}$.

2. From the viewpoint of the relationship between the temperature and thermal stress, when the temperature is below $420{ }^{\circ} \mathrm{C}$, the thermal stress of tungsten armor will increase with increasing temperature. The thermal stress will decrease with increasing temperature at 420-1050 ${ }^{\circ} \mathrm{C}$. Eventually, the thermal stress tends to be stabilized when the temperature on the top surface exceeds $1050{ }^{\circ} \mathrm{C}$. Therefore, it is necessary for reducing the risk of fatigue crack induced by constantly changing thermal stress to control the top surface temperature of $\mathrm{PFC}$ at $1050-3420^{\circ} \mathrm{C}$.

3. The SCZ always grows on the surface of tungsten armor when the heat flux is less than $3 \mathrm{MW} / \mathrm{m}^{2}$ (stress value is about $940 \mathrm{MPa}$ ); and when the heat flux increases from 3 to $9 \mathrm{MW} / \mathrm{m}^{2}$, the $\mathrm{SCZ}$ will move gradually toward OFHC-Cu interlayer with the increase in heat flux. When the heat flux is more than $9 \mathrm{MW} / \mathrm{m}^{2}$, the SCZ is always at the junction between tungsten armor layer and OFHC-Cu interlayer, and the stress concentration phenomenon will fade with the increase in heat flux. Finally, the stress concentration phenomenon will disappear, when the heat flux is up to $25 \mathrm{MW} / \mathrm{m}^{2}$. In other words, the whole $\mathrm{W}$ armor will yield, when the heat flux reaches $25 \mathrm{MW} / \mathrm{m}^{2}$ and the stress value is about $470 \mathrm{MPa}$.

4. Combining the results of FE simulation and MansonCoffin equation, we can predict that the fatigue crack is very likely to initiate at the central area of tungsten surface, and the growth direction of the crack is in the direction of cooling tube axis. Moreover, the fatigue lifetime of $\mathrm{W}$ decreases exponentially with increasing heat flux, and the fatigue lifetime of tungsten is about 330 , when the heat flux is up to $20 \mathrm{MW} / \mathrm{m}^{2}$.

Acknowledgements The authors gratefully acknowledge the financial supports from the ITER-National Magnetic Confinement Fusion Program (Nos. 2014 GB123000 and 2010 GB109000) and the National Natural Science Foundation of China (No. 51172016).

\section{References}

[1] B. He, B. Huang, Y. Xiao, Y.Y. Lian, X. Liu, J. Tang, J. Alloys Compd. 686, 298 (2016)

[2] W.Z. Tang, L. Yang, W. Zhu, Y.C. Zhou, J.W. Guo, C. Lu, J. Mater. Sci. Technol. 32, 452 (2016)

[3] L.L. Snead, T.D. Burchell, Y. Katoh, J. Nucl. Mater. 381, 55 (2008)

[4] T. Hirai, K. Ezato, P. Majerus, Mater. Trans. 46, 412 (2005)

[5] H. Bolt, V. Barabash, G. Federici, J. Linke, A. Loarte, J. Roth, K. Sato, J. Nucl. Mater. 307-311, 43 (2002)

[6] R. Liu, Z.M. Xie, Q.F. Fang, T. Zhang, X.P. Wang, T. Hao, C.S. Liu, Y. Dai, J. Alloys Compd. 657, 73 (2016)

[7] M. Li, E. Werner, J.H. You, Nucl. Mater. Energy 2, 1 (2015)

[8] C.X. Sun, S.M. Wang, W.H. Guo, W.P. Shen, C.C. Ge, J. Mater. Sci. Technol. 30, 1230 (2014)

[9] A. Jafari, M. Ghoranneviss, S. Meshkani, J. Fusion. Energy 35, 306 (2016)

[10] M. Lipa, A. Durocher, R. Tivey, T. Hubber, B. Schedler, J. Weigert, Fusion Eng. Des. 75-79, 469 (2005)

[11] D.D. Qu, Z.J. Zhou, Y.J. Yum, J. Aktaa, J. Nucl. Mater. 455, 130 (2014)

[12] X. Chen, F. Ding, H. Mao, G. Luo, Z. Hu, F. Xu, G. Niu, M. Roeding, W. Kuehnlein, J. Linke, M. Merola, E. Rigal, B. Schedler, E. Visca, Fusion Eng. Des. 108, 98 (2016)

[13] G. Dell'Orco, P. Lorenzetto, A. Malavasi, G. Polazzi, M. Simoncini, G. Venturi, D. Zito, Fusion Eng. Des. 61-62, 117 (2002)

[14] T. Hirai, G. Pintsuk, Fusion Eng. Des. 82, 389 (2007)

[15] M. Roeding, W. Kuehnlein, J. Linke, M. Merola, E. Rigal, B. Schedler, E. Visca, Fusion Eng. Des. 61-62, 135 (2002)

[16] S.H. Huang, Y.Q. Zhao, W.H. Wang, Sci. China Technol. Sci. 59, 476 (2016)

[17] P. Gavila, B. Riccardi, G. Pintsuk, G. Ritz, V. Kuznetsov, A. Durocher, Fusion Eng. Des. 98-99, 1305 (2015)

[18] P. Lorenzetto, A. Cardella, W. Daenner, M. Febvre, A. Llzheofer, W. Richards, M. Roedig, Fusion Eng. Des. 61-62, 643 (2002)

[19] R.N. Giniyatulin, V.L. Komarov, E.G. Kuzmin, A.N. Makhankov, I.V. Mazul, N.A. Yablokov, A.N. Zhuk, Fusion Eng. Des. 61-62, 185 (2002) 
[20] E. Madenci, I. Guven, The Finite Element Method and Applications in Engineering Using ANSYS ${ }^{\circledR}$ (Springer, Berlin, 2015)

[21] Z. Jin, K. Yin, K. Yan, D. Wu, J. Liu, Z. Cui, J. Mater. Sci. Technol. 33, 1255 (2017)

[22] S. Moaveni, Finite Element Analysis: Theory and Application with ANSYS (Pearson Education, Delhi, 2003)

[23] ANSYS User's Manual. (ANSYS Inc., Houston, 2005)

[24] J.W. Davis, ITER Material Properties Handbook, Publication Package 3, S74RE1 97-08-01W1.6. (International Atomic Energy Agency, Vienna, 1997)

[25] J.H. You, M. Miskiewicz, J. Nucl. Mater. 373, 269 (2008)

[26] Y.J. Hu, S.L. Shang, Y. Wang, K.A. Darling, B.G. Butler, L.J. Kecskes, Z.K. Liu, J. Alloys Compd. 671, 267 (2016)

[27] M.Y. Li, J.H. You, Fusion Eng. Des. 101, 1 (2015)
[28] S.H. Huang, Y.Q. Zhao, W.H. Wang, J. Fusion. Energy 34, 1465 (2015)

[29] ITER Director, ITER document G A0 FDR, (2001), pp. 20-39

[30] F.P. Incropera, D.P. DeWitt, Introduction to Heat Transfer, Forth edn. (Wiley, New York, 2002), pp. 459-463

[31] Y. Wang, S. Wang, Q. Ye, Q. Yan, C. Ge, J. Mater. Sci. Technol. 32, 1386 (2016)

[32] G. Halford, S.S. Manson, A method of estimating high temperature low cycle fatigue behavior of materials. U.S. Patent no. NASA-TM-X-52770

[33] N. Jaksic, H. Greuner, A. Herrmann, Fusion Eng. Des. 88, 1789 (2013)

[34] D.H. Lassila, G.T. Gray III, J. Phys. IV. 4, 354 (1994) 